\title{
Hepatitis $\mathrm{E}$ - effect on the liver and beyond
}

\author{
Mihaela Catalina Luca',2, Ioana-Alina Harja-Alexa', Stefana Luca', \\ Georgiana Leonte-Enache ${ }^{1,2}$, Adelina Matei ${ }^{2}$, Andrei Vata ${ }^{1,2}$ \\ 1"Grigore T. Popa" University of Medicine and Pharmacy lasi, Romania \\ 2"Saint Parascheva" Clinical Hospital of Infectious Diseases Iasi, Romania
}

\begin{abstract}
Introduction. Hepatitis $E$ is an acute liver disease caused by $E$ hepatitis virus (HEV), representing a global public health problem comparable with other transmissible infections. Aim. The purpose of this paper is to present the epidemiological, clinical, biological and evolutive aspects of HEV infection.

Material and method. An estimated 20 million infections are annually reported worldwide with higher prevalence rates recorded in South-East Asia (over $60 \%$ of infections and over $65 \%$ of HEV related deaths). In Romania the incidence of HEV in 2009 was $12 \%$, the frequency of infection being limited to the anti-HEV specific IgG antibodies seroprevalence.

Results. HEV transmission is predominantly by digestive tract (especially contaminated water) but also by blood, plasma, organ transplant. The incubation period ranges from 21 to 45 days, onset of gastrointestinal simptoms, fever, influenza-like syndrome, asthenia, skin rush, weight loss, abdominal pain, dehydration. The state period is characterized by sclero-tegumentary jaundice ( $75 \%$ cases), skin pruritus, steathoresis, dark urine and pale stools. HEV can cause extrahepatic manifestations (neurological, renal lesions, pancreatitis and haematological disturbencies). Farmacological treatment of HEV infection includes Peg-Inf, Ribavirin and also newest DAAs agents. Discussions. In most patients hepatitis E causes a self-limited disease that lasts for several weeks. Acute infection is generally asymptomatic and is caused by genotype 1 in young people, while genotypes 3 and 4 generally affect immunosuppressed patients. Chronic infection is caused by genotypes 3 and 4 in immunosuppressed pacients (transplanted, HIV-positive and haematological patients) and has a lower incidence and mortality. Evolution of viral hepatitis $\mathrm{E}$ may be severe and fulminant due to acute liver failure. A recombinant vaccine approved in China in 2011 opens up prospects for the specific prevention measures in areas identified as being at risk to limit the consequences of hepatitis $E$ virus infection in the general population and exposed groups. Conclusions. Hepatitis $\mathrm{E}$ management involves the therapy of chronic infection in immunosuppressed patients, the extrahepatic manifestations and also acute severe HEV infections.
\end{abstract}

Keywords: hepatitis E virus, genotypes, immunosuppressed host, treatment

Hepatitis $\mathrm{E}$ is an acute liver disease caused by $\mathrm{E}$ hepatitis virus (HEV) with symptoms similar to those seen in hepatitis A virus infections. Hepatitis $\mathrm{E}$ is transmitted through contaminated water or food, representing a global public health problem comparable with other transmissible infections.

Although it does not usually lead to chronic liver infections, it rarely can lead to serious liver problems. Hepatitis E virus, discovered in 1983 by investigators of an unexplained hepatitis outbreak in Soviet soldiers in Afghanistan, is a small tiny particle that is part of the Hepeviridae family. The genome is about 7200 bases long being a single-stranded RNA molecule (Fig. 1).

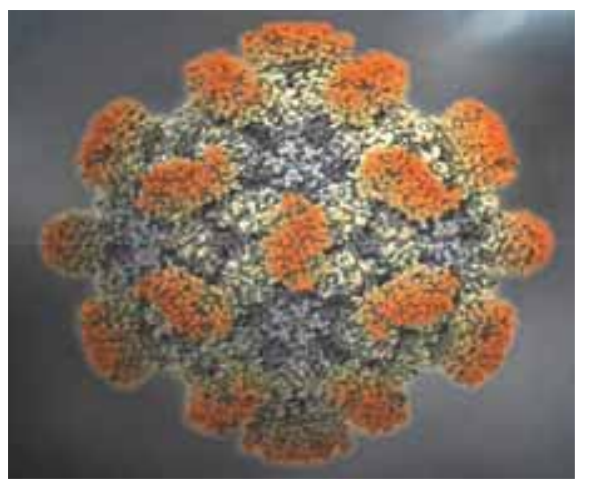

FIGURE 1. Hepatitis E virus

An estimated 20 million infections are annually reported worldwide with higher prevalence rates 
recorded in South-East Asia (over 60\% of infections and over $65 \%$ of HEV related deaths). In Egypt, $50 \%$ of the population over 5 years old is serologically positive for HEV. Mortality in the general population varies between $0.5 \%$ and $4 \%$ and represents $3.3 \%$ of the overall mortality rate, accounting for approximately 56.600 deaths, but may reach up to $25 \%$ in pregnant women. It is estimated that there are approximately 3 million symptomatic cases worldwide.

Hepatitis E is more common in Asia where is endemic-epidemic, but cases are also noted in developed European countries (e.g. France, Germany and England). $80 \%$ of cases of HEV infection have been reported in Germany, France and England by implementing the surveillance system for this disease since 2005 (7). However the incidence of $\mathrm{HEV}$ infection in the EU is still uncertain due to limitation of surveillance systems, differences in the etiological diagnostic tests and the lack of information. An increased rate of HEV positive serology in young blood donors has recently been found in Netherlands, Germany and England. The incidence of cases decreased from $80 \%$ in 2005 to $55 \%$ in 2015. On the other side in patients aged over 50 years old the incidence increased from $30-45 \%$ between 2005 and 2008 to over $60 \%$ between 2013 and 2015, fact which highlights the dynamics of this emerging epidemiological phenomenon. The number of HEV related deaths increased from 0-1 cases per year between 2005 and 2008 to 4-8 cases per year during the period 2012-2015.

In Romania the incidence of HEV in 2009 was $12 \%$, the frequency of infection being limited to the

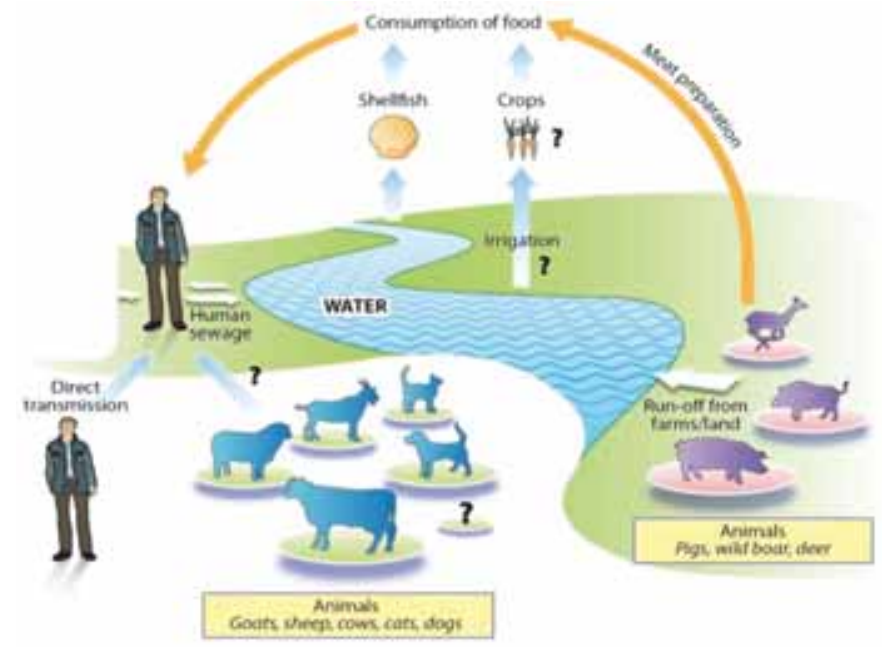

anti-HEV specific IgG antibodies seroprevalence. In a study performed on students and medical staff the prevalence of these antibodies was $12.5 \%$ and $14 \%$, respectively (1).

HEV transmission is predominantly by digestive tract (especially contaminated water) but also by blood, plasma, organ transplant. The number of outbreaks increased from 0-3 per year between 2005 and 2010, 6 in 2014, 9 in 2015, up to 47 cases (outbreak in 2017). Although originally thought to be limited to human-to-human spread, HEV also occurs between animals and, more importantly, as zoonotic spread from animals to humans (Fig. 2).

Only one serotype and four major genotypes (1-4) of have are known. Genotype 3 predominates in developed countries with zoonotic transmission and mainly related to pork, but also wild boar, deer or crustaceans.

Genotypes 3 and 4 predominate in Europe. Cases associated with journeys in current endemic areas could be determined by genotypes 1, 2 or 4 . The four genotypes of HEV have different clinical implications (Fig. 3).

Acute infection is generally asymptomatic and is caused by genotype 1 in young people, while genotypes 3 and 4 generally affect immunosuppressed patients. Increased mortality was seen in pregnant women and people with chronic liver disease. A mortality up to $25 \%$ related to fulminant form (acute liver failure) is predominantly determined by genotype 1 especially in pregnant women.

Chronic form is defined by the persistence of viral replication 3 months after infection. Chronic infection is caused by genotypes 3 and 4 in immu-

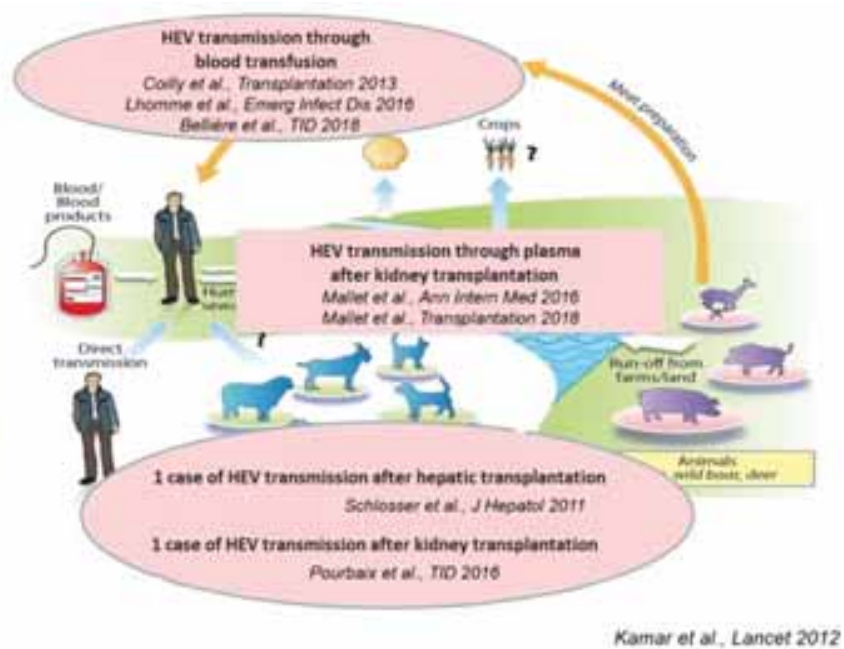

FIGURE 2. Zoonotic spread from animals to humans 


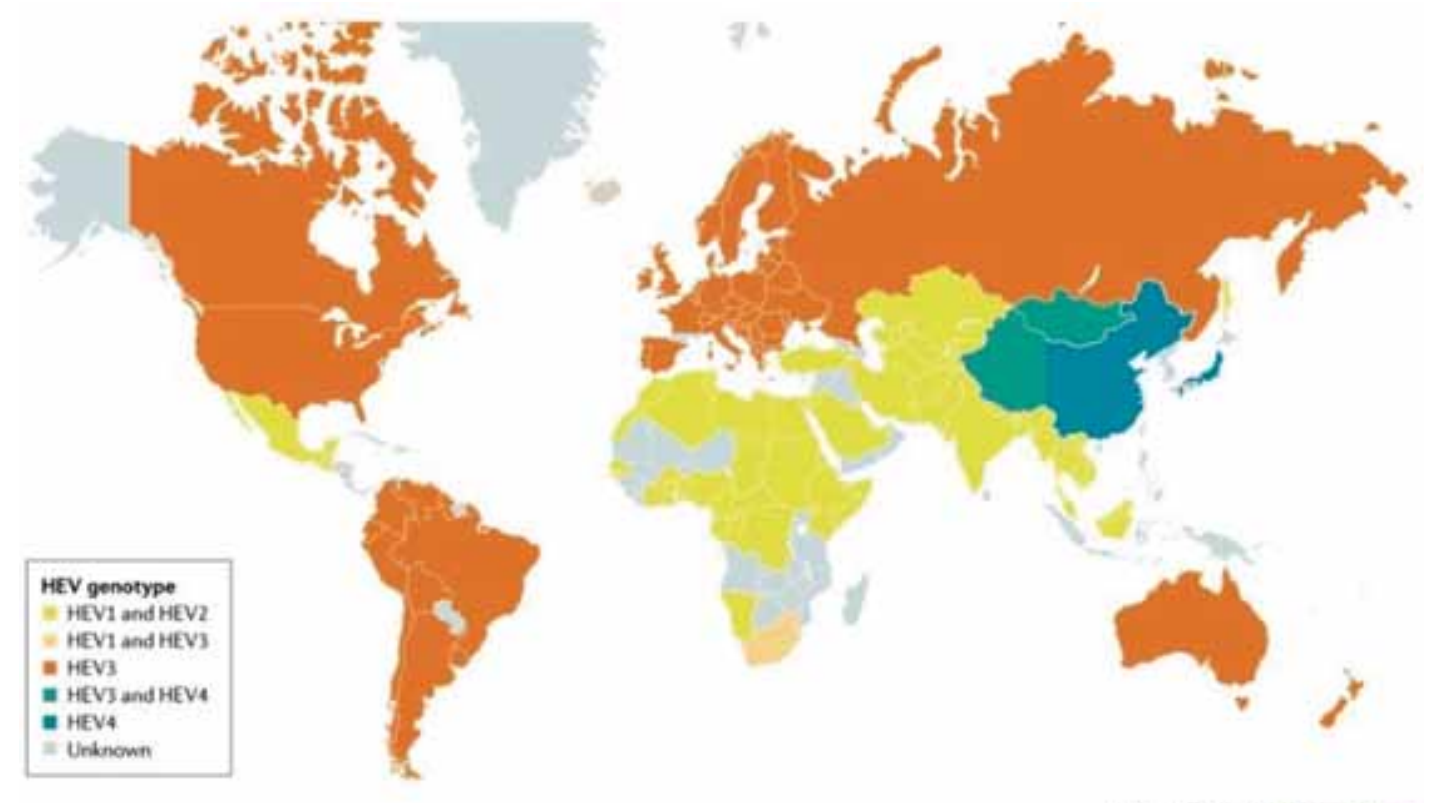

Nature Reviews | Disease Frimen

Kamar, N et al. (2017) Hepatitis E virus infection Nat Rev Dis. Primers doi 10.1038/nrdp 2017.86

FIGURE 3. Clinical implications of the four genotypes of HEV

nosupressed patients (transplanted, HIV-positive and hematological patients) and has a lower incidence and mortality. Chronic HEV infection with genotypes 1 and 2 is not documented. In a recent study of 205 patients with renal transplant in India no evidence of chronic HEV infection was found in an area with high disease endemicity of genotype 1 (7) .

In most patients hepatitis E causes a self-limited disease that lasts for several weeks. Most cases are asymptomatic. The incubation period ranges from 21 to 45 days, followed by the onset of gastrointestinal symptoms, fever, influenza-like syndrome, asthenia, skin rash, weight loss, abdominal pain, dehydration. The state period is characterized by jaundice ( $75 \%$ cases), skin pruritus, steatorrho- ea, dark urine and pale stools. ALAT has values of 1,000-3,000 IU/1, and recovery takes place in 4-6 weeks. Natural history and prognosis are different: patients with chronic liver disease have an unfavorable prognosis and immunosuppressed people often develop chronic infections (Fig. 4).

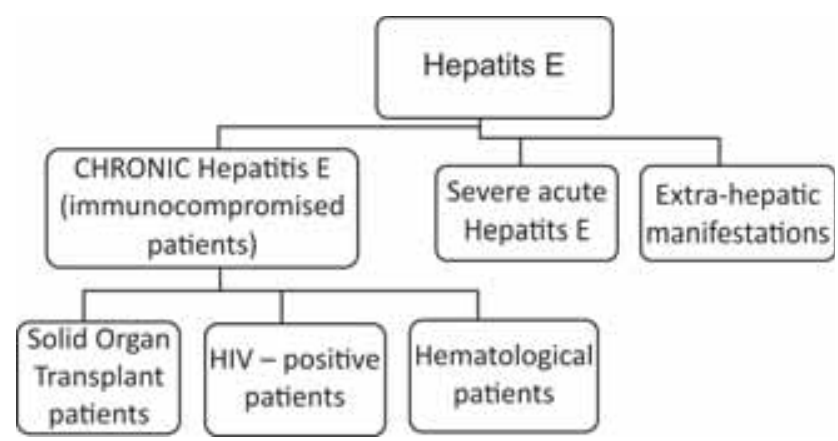

FIGURE 4. Natural history of HEV infection

TABLE 1. Chronic HEV infection

\begin{tabular}{|c|c|c|c|}
\hline & GENOT1P 1 & GENOT1P 3 & GENOT1P4 \\
\hline \multirow{4}{*}{$\begin{array}{l}\text { ACUTE LIVER } \\
\text { FAILURE }\end{array}$} & - Appears in pregnancy & - Cohort studies & - Chinese study \\
\hline & - Mortality up to $25 \%$ & - Scotland 2,5\% HEV, without deaths & - Incidence $4,1 \%$ \\
\hline & & - Germany $10 \%$ HEV, 1 death & - Mortality 2,2\% \\
\hline & & • no death on pregnancy & - no death on pregnancy \\
\hline \multirow{4}{*}{$\begin{array}{l}\text { DECOMPENSATED } \\
\text { CHRONIC LIVER } \\
\text { FAILUIRE }\end{array}$} & - Cohort studies & - Anglo-French study & - Incidence 9\% \\
\hline & - Mortality up to $70 \%$ & - $2,9 \% \mathrm{HEV}$ & - Mortality 9\% \\
\hline & & - 3 deaths & - 1 pregnancy death \\
\hline & \begin{tabular}{|l|} 
Rein et al Hepatology 2012 \\
Kamar et al Lancet 2012 \\
Gumar Acharya J Hepatol 2007
\end{tabular} & \begin{tabular}{|l|} 
Crossan et al WJH 2014 \\
Manka et al Clin GastroHepatol 2015 \\
Blascoe Perri et al APT 2015
\end{tabular} & Liu et al Int J Inf Dis 2018 \\
\hline
\end{tabular}


HEV can cause extrahepatic manifestations (neurological, renal lesions, pancreatitis and hematologic disturbances) (Table 2).

TABLE 2. Extra-hepatic manifestations of HEV infection

\begin{tabular}{|c|c|c|}
\hline \begin{tabular}{|l}
$\begin{array}{l}\text { Acute } \\
\text { pancreatitis }\end{array}$ \\
\end{tabular} & & \\
\hline Musculoskeletal & $\begin{array}{l}\text { Nectrotizing myositis } \\
\text { Pyomyositis }\end{array}$ & \\
\hline Hematological & $\begin{array}{l}\text { Hemolytic anemia } \\
\text { Aplastic anemia } \\
\text { Pure red-cell aplasia } \\
\text { Severe thrombocytopenia } \\
\text { Hematophagocytic } \\
\text { syndrome }\end{array}$ & $\begin{array}{l}\text { G6PD deficiency } \\
\text { Auto-immune }\end{array}$ \\
\hline Renal & $\begin{array}{l}\text { Decreased eGFR } \\
\text { Glomerulopephritis } \pm \\
\text { cryoglobulinemia }\end{array}$ & $\begin{array}{l}\text { Membranous } \\
\text { glomerulonephritis } \\
\text { Membranoproliferative } \\
\text { glomerulonephritis } \\
\text { IgA nephropathy } \\
\text { Nephroangiosclerosis } \\
\end{array}$ \\
\hline $\begin{array}{l}\text { Other } \\
\text { immunemediated }\end{array}$ & \begin{tabular}{|l} 
Thyroidis \\
Myocarditis \\
Henoch-Schönlein purpura \\
Myasthenia gravis
\end{tabular} & \\
\hline
\end{tabular}

Neurological disorders (e.g. Guillain-Barré syndrome, Bell paralysis, neuralgic amyotrophy, acute transverse myelitis and acute meningoencephalitis) may be caused by HEV1 or HEV3 genotypes.

Neurological symptoms for HVE1 and for acute and chronic HVE3 infections have been described. When this occurs, the diagnosis can easily be overlooked because the neurological symptoms dominate the clinical picture (10). Neurological manifestations observed in HVE patients include Guillain-Barré syndrome, Bell paralysis, neuralgic amyotrophy, acute transverse myelitis and acute meningoencephalitis (Figure 4). In a retrospective analysis of 126 patients with VHE, neurological symptoms were observed in 7 patients $(5.5 \%)$, including 3 immunocompetent patients with acute infection, 3 patients with solid organ transplant (SOT) and 1 HIV patient -position with chronic infection.

Recently Guillain-Barré syndrome associated with necrotizing myositis has been described in a patient with liver transplant. HEV RNA in the CSF has been documented in all patients with chronic HEV infection associating with neurological syndromes (10). In one patient with kidney transplantation, chronic hepatitis and neurological symptoms, clonal sequences of the CSF and serum showed the presence of quasispecies, suggesting that HEV associated neurological lesions may be related to neurotropic variants. Recently, cases of Guillain-Barré anti-ganglioside GM1- and GM2positive syndrome associated with $\mathrm{HEV}$ infection have been described (11).

A study performed in 2017 on mice demonstrated that HEV crosses the blood-brain barrier (Fig. 5).

Impaired renal function was observed in both acute and chronic HEV infections, HEV 1 and 3 may cause glomerular disease. There are two different histological models of glomerular disease - membrano-proliferative glomerulonephritis and membranous glomerulonephritis- which have been observed in both immunocompetent patients and in kidney or liver transplanted patients. The pathophysiological mechanisms of HEV related renal lesions are uncertain but cryoglobulinemia may play an important role in patients with chronic infection (12).

Neurological manifestations
- Guillain Barré syndrome-36
- Neuralgic amiotrophy-21
- Encephalitis - 8
- Other manifestations
Bell paralysis
Transverse myelitis
Polyradiculopathy
Peripheral neuropathy
Myasthenia gravis
Paresthesia
Vestibular neuritis

Neurological manifestations

- Guillain Barré syndrome-36

- Neuralgic amiotrophy -21

- Other manifestations

Bell paralysis

Transverse myelitis

Polyradiculopathy

Myasthenia gravis

Vestibular neuritis
Geographical distribution

Europe -63 cases

- Belgium

- France

- Germany

- Ireland

- Portugal

- UK

- Scotland

- Netherlands

Asia - 21 cases

- Bangladesh

- China

- Hong Kong

- India

- Thailand

USA - 1 case
FIGURE 5. Neurological manifestations in HEV infection 


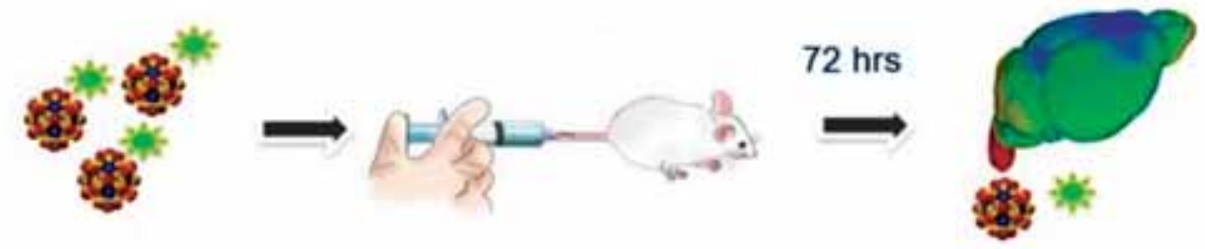

FIGURE 6. HEV crosses the blood-brain barrier (Xhou et al J Inf Dis 2017)

Acute pancreatitis has been associated with HEV1 infection and has not been reported in any of the other genotypes. Thrombocytopenia and aplastic anemia have been reported in acute HEV infection (13).

Studies in developing countries have shown an increase mortality rate up to $20-25 \%$ in HEV infected pregnant women usually in the third trimester of pregnancy. Obstetrical complications (hemorrhage or eclampsia) or fulminant hepatic impairment may cause dead in this patients. HEV infection during pregnancy was associated with fetal death but also with an increased neonatal morbidity and mortality as a result of vertical transmission.

The cause of over-counted maternal mortality in HEV infected patients is uncertain and has been the subject of numerous studies and debates. Pregnancy is characterized by a state of maternal immune tolerance to the fetus. T cell activity is reduced, and there is also a reduction in cytokine production in the first 20 weeks, predominating Th2 responses. Changes in maternal immunological responses are partly determined by significant changes in hormonal profiles with increased levels of progesterone, estrogen and human chorionic gonadotropin. There are significant differences in immunological and hormonal responses in pregnant women with fulminant hepatic impairment caused by HEV infection (14). Recent studies revealed higher HEV viral loads in pregnant versus non-pregnant women (15).

HEV infected patients with chronic liver disease have unfavorable prognosis since they frequently develop acute or subacute hepatic failure. In an Indian cohort study on patients with chronic liver disease, HEV related decompensation has a significantly worse prognosis compared to other causes. The 12-month mortality in the HEV cohort was $70 \%$. In developed countries there is a strong relationship between deaths from chronic decompensated liver disease and consumption of pork. The rea- son is uncertain but can be explained by an unrecognized infection with HEV. Studies of this assumption are ongoing, in one of these studies being followed the natural evolution of HEV3 infection in patients with solid organ transplantation. Chronic infection has been identified in immunosuppressed subjects in the context of immunosuppressive therapy including organ transplantation (16).

The incidence of HEV and HIV co-infections low (0-1.3\%). HEV 3 genotype was revealed by PCR in HIV-positive patients. In literature are mentioned some cases of hepatic cirrhosis in patients with HEV and HIV co-infection. Also cases of chronic HEV infection have been reported in hematological patients (T-cell lymphoma; nonHodgkin's lymphoma treated with Rituximab; untreated patients with hairy cell leukemia; idiopathic T CD4 lymphopenia; chronic myelomonocytic leukemia; chronic lymphocytic leukemia). Chronic $\mathrm{HEV}$ infection was also noted in post-transplant stem cells patients.

RT-PCR is the method of choice to identify circulating HEV RNA, as well as genotype determination. Epidemiological context of potential transmission from domestic, peridomesic and wild animals in humans has an important diagnostic value. Among the non-specific paraclinical investigations we mention the full blood count (possible aplastic anemia), decrease of the prothrombin level $(<50 \%$ in regular disease, $<25 \%$ in fulminant forms); hepatocytolisis (with increased transaminases) and cholestatic syndrome (Fig. 6).

Anti-HEV IgG level is a useful tool to indentify the immune status that reliable prevents HEV from natural infections or vaccine administration. The vaccine study suggested that an antibody titer of $2.5 \mathrm{U} / \mathrm{ml}$ was found protective. IgG protection is not specific. A HEV 1 genotype recombinant vaccine also prevented genotype 1 and 4 infections, indi- 
cating cross-protection against various HEV genotypes. In patients with acute hepatic infection the peak of viremia is maximal during the incubation period and during the early symptomatic phase. RNA-HEV becomes undetectable in the blood approximately 3 weeks after the onset of symptoms but can be detected in the faeces for a further 2 weeks. If patients are tested late in the symptomatic phase of the disease, a negative HEV RNA result does not rule out the recent infection. Serum concentrations of RNA in the acute phase were between 2.1 and 8.3 copies / $\mathrm{ml}$ in immunocompetent patients. There is no relationship between the serum RNA concentration and clinical symptoms. In transplanted patients with acute hepatitis E, the HEV RNA level varied between 2.7 and 7.8 copies/ $\mathrm{ml}$ and was not associated with the progression to chronic infections (18).

Differential diagnosis is made with other infectious diseases: leptospirosis, brucellosis, other viral hepatitis (HAV, HCV, HBV), toxoplasmosis and non-infectious diseases (e.g.toxic hepatitis, alcoholic hepatitis, autoimmune hepatitis, angiocollitis, Budd-Chiari syndrome, haemochromatosis, Wilson's disease). Evolution of viral hepatitis E may be severe and fulminant due to acute liver failure.

Hepatitis E management involves the therapy of chronic infection in immunosuppressed patients, the extrahepatic manifestations and also acute severe HEV infections (Fig. 7).

Pharmacological treatment of HEV infection includes Peg-Interferon, Ribavirin and also newest
DAAs agents. Ribavirin inhibits HEV replication by exhausting GTP channels. A multicenter study in France on 59 patients with solid organ transplantation and chronic HEV shows $85 \%$ SVR at the end of Ribavirin therapy (Fig. 8).

An alternative treatment for Ribavirin for HEV transplant patients is Peg-IFN monotherapy. The newest alternatives of treatment include interferon free regimen, for exemple Sofosbuvir inhibits HEV replication in vitro with a potentiating effect in combination with Ribavirin (Fig. 9).

Evolution of viral hepatitis $\mathbf{E}$ may be severe and fulminant due to acute liver failure. The importance of preventing and controlling this infection is more justified for reducing overall mortality and maternal-fetal mortality. A $27 \%$ mortality rate was reported in patients with pre-existing chronic liver disease (2).

In line with the current concept, efforts in the field of human medicine and public health should be linked to additional measures for food safety and the environment, such as the identification of hepatitis $\mathrm{E}$ virus genotypes 3 and 4 in different pork foods and seafood, to assess the incidence of these genotypes that could be responsible for most cases of disease in Europe. It is also necessary to monitor the circulation of HEV in wildlife surface waters (3).

HEV prevention is based on maintaining drinking water, proper sanitation conditions, adherence to personal hygiene rules, and avoiding the use of undercooked fish, unroasted nuts and fruits especially in endemic countries (4). A recombinant
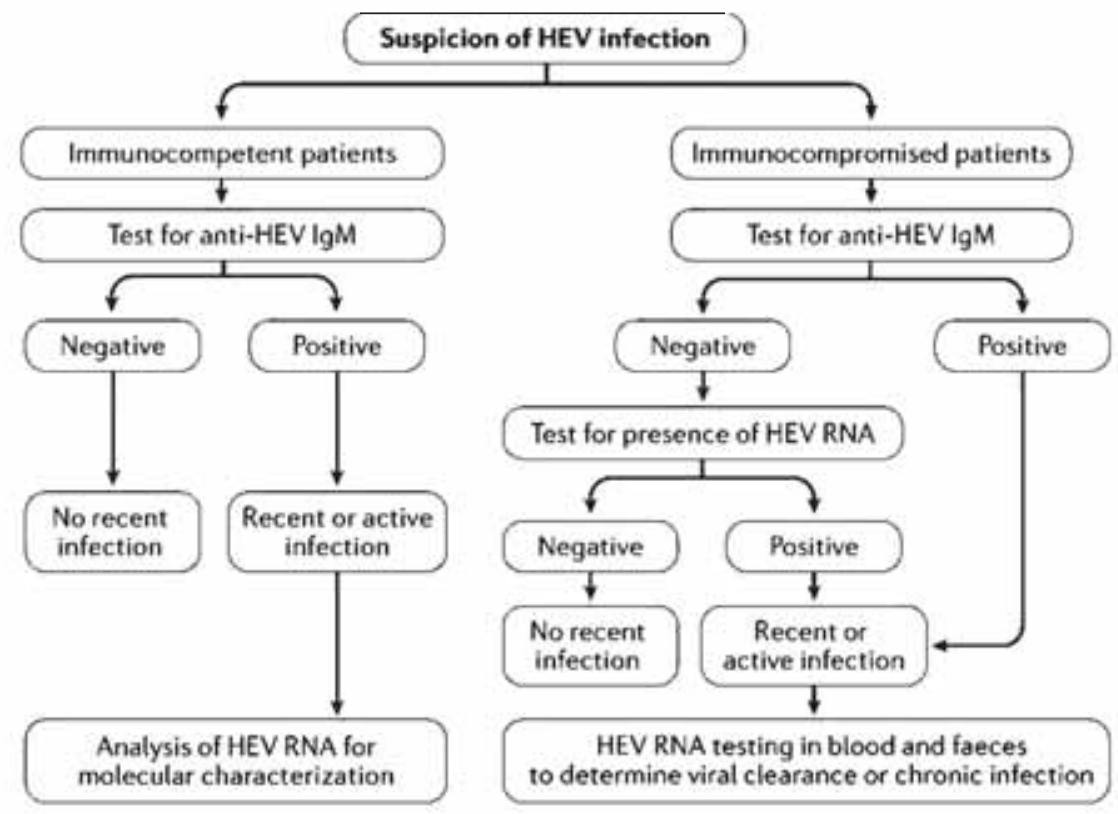

FIGURE 7. Diagnostic algorithm for HEV infection 


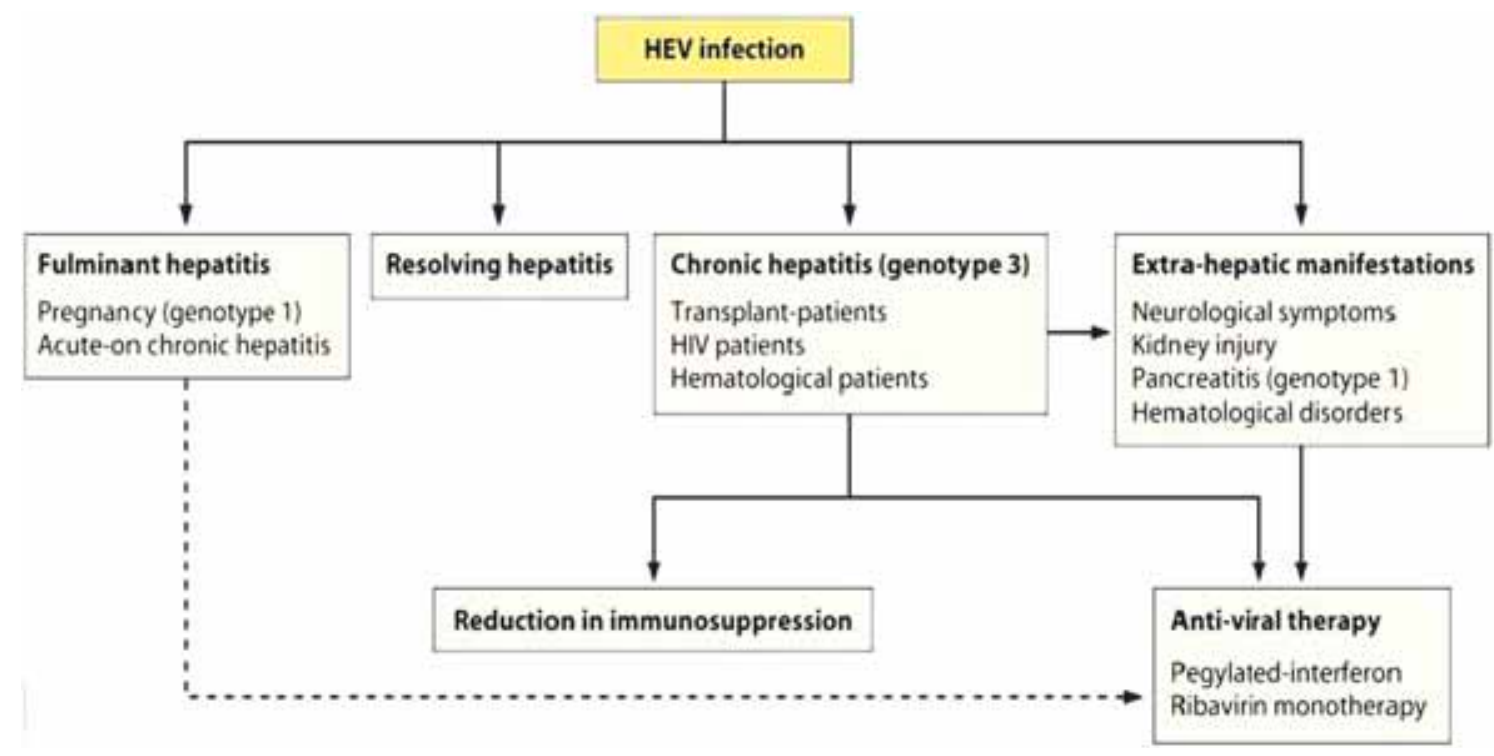

FIGURE 8. Hepatitis E management

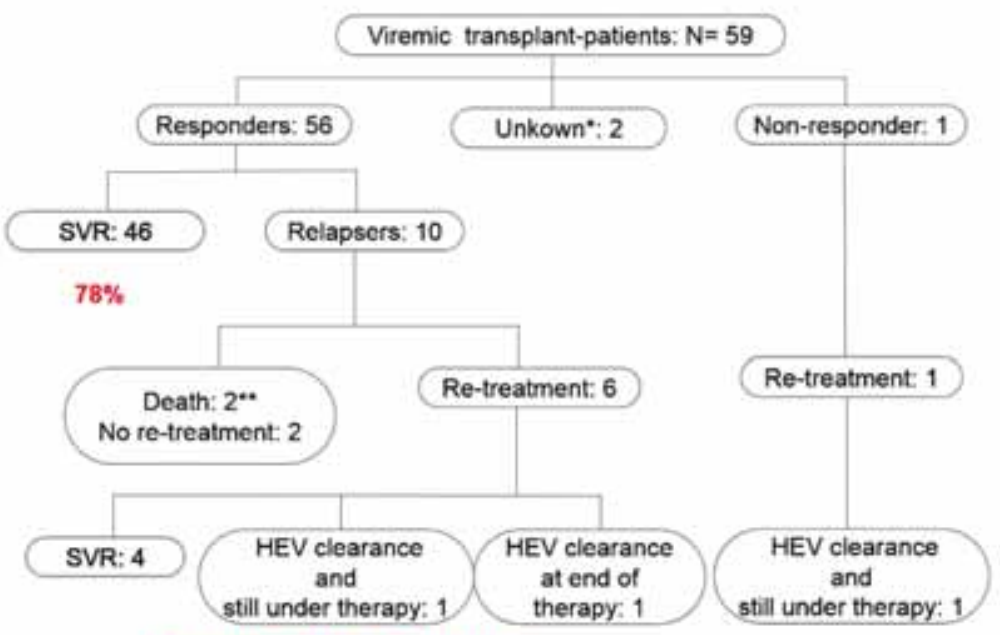

Overall, SVR: 50/59: 85\% Kamar ef al, N Engl J Med 2014

FIGURE 9. The results of the multicenter study in France

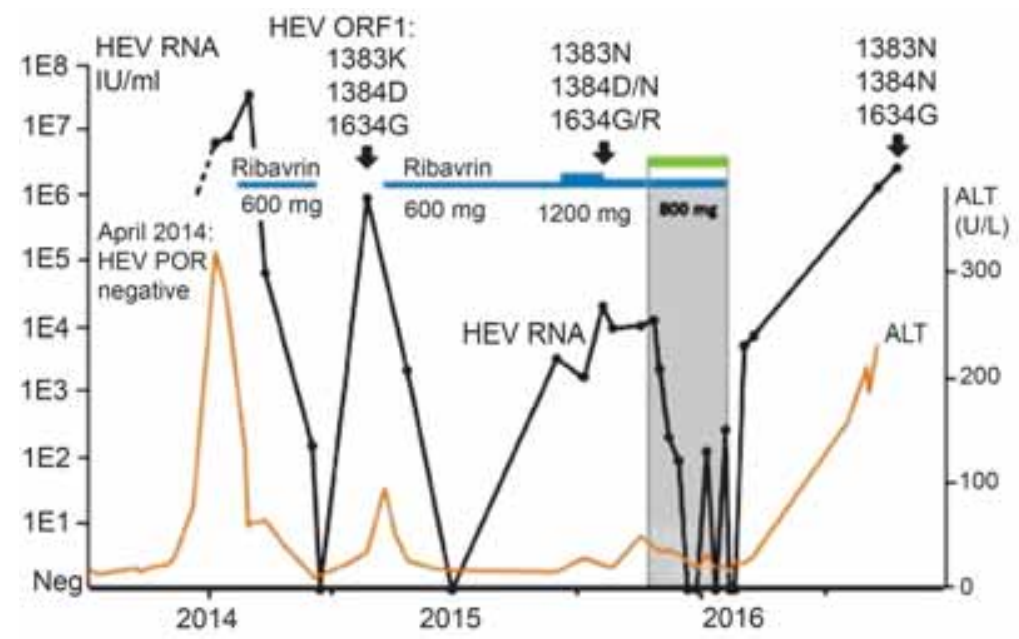

FIGURE 10. Virological response rates for treatment in transplant patients (Van der Valk et al.) 
vaccine approved in China in 2011 opens up prospects for these specific prevention measures in areas identified as being at risk to limit the consequences of hepatitis E virus infection in the general population and exposed groups (5).

\section{REFERENCES}

1. Lapa D, Capobianchi MR, Garbuglia AR. Epidemiology of Hepatitis E Virus in European Countries. Int.J.Molec Sci., 2015, 16 (10): 25711-25743

2. Adlhoch C, Avellon A, Baylis SA și colab. Hepatitis E virus: Assessment of the epidemiological situation in humans in Europe, 2014/15. J.Clin.Virol., 2016, 82: 9-16.

3. Echevarria JM. Autochthonous Hepatitis E Virus Infection in Europe: A Matter of Concern for Public Health? J.Clin. Trans/Hepatol. 2014; 2 : 7-14.

4. Centrul European de Prevenire și Control al Bolilor. Hepatita E în UE I SEE, 2005-2015, Stockholm: ECDC, 2017

5. OMS, Hépatite E. Aide-mémoire nr. 280, Juillet 2017

6. Balayan MS, Andjaparidze AG, Savinskaya SS, Ketiladze ES, Braginsky DM, Savinov AP, Poleschuk VF.. Evidence for a virus in non-A, non-B hepatitis transmitted via the fecal-oral route. Intervirology. 1983; 20:23-31.

7. Nassim Kamar, Harry R. Dalton, Florence Abravane Hepatitis E Virus Infection, Clin Microbiol Rev. 2014 Jan; 27(1): 116-138.

8. Naik A, Gupta N, Goel D, Ippagunta SK, Sharma RK, Aggarwal R.. Lack of evidence of hepatitis $E$ virus infection among renal transplant recipients in a disease-endemic area. J. Viral Hepat. 2013; 20:e138e140

9. Dalton HR, Fellows HJ, Gane EJ, Wong P, Gerred S, Schroeder B, Croxson MC, Garkavenko O.. Hepatitis E in New Zealand. J. Gastroenterol. Hepatol. 2007; 22:1236-1240.

10. Kamar N, Bendall RP, Peron JM, Cintas P, Prudhomme L, Mansuy JM, Rostaing L, Keane F, ljaz S, Izopet J, Dalton HR.. Hepatitis E virus and neurologic disorders. Emerg. Infect. Dis. 2011; 17:173-179.

11. Kamar N, Izopet J, Cintas P, Garrouste C, Uro-Coste E, Cointault O, Rostaing L.. Hepatitis E virus-induced neurological symptoms in a kidney-transplant patient with chronic hepatitis. Am. J. Transplant. 2010; 10:1321-1324.

12. Kamar $N$, Weclawiack $H$, Guilbeaud-Frugier $C$, Legrand-Abravanel $F$, Cointault O, Ribes D, Esposito L, Cardeau I, Guitard J, Sallusto F,
New safety criteria are needed from blood donors in general population to limit the risk of $\mathrm{HEV}$ transmission the general population and for the different categories of people at risk.
Muscari F, Peron JM, Alric L, Izopet J, Rostaing L.. Hepatitis E virus and the kidney in solid-organ-transplant patients. Transplantation 2012; 93:617-623

13. Shah SA, Lal A, Idrees M, Hussain A, Jeet C, Malik FA, Iqbal Z, Rehman H.. Hepatitis E virus-associated aplastic anaemia: The first case of its kind. J. Clin. Virol. 2012; 54:96-97

14. Salam GD, Kumar A, Kar P, Aggarwal S, Husain A, Sharma S.. Serum tumor necrosis factor-alpha level in hepatitis $E$ virus-related acute viral hepatitis and fulminant hepatic failure in pregnant women. Hepatol. Res. 2013; 43:826-835

15. 1Kar P, Jilani N, Husain SA, Pasha ST, Anand R, Rai A, Das BC.. Does hepatitis $E$ viral load and genotypes influence the final outcome of acute liver failure during pregnancy? Am. J. Gastroenterol. 2008

16. Dalton HR, Hazeldine S, Banks M, ljaz S, Bendall R.. Locally acquired hepatitis $E$ in chronic liver disease. Lancet 2007; 369:1260.

17. Innis BL, Seriwatana J, Robinson RA, Shrestha MP, Yarbough PO, Longer CF, Scott RM, Vaughn DW, Myint KS.. Quantitation of immunoglobulin to hepatitis $E$ virus by enzyme immunoassay. Clin. Diagn. Lab. Immunol. 2002; 9:639-648.

18. Abravanel F, Chapuy-Regaud S, Lhomme S, Miedouge M, Peron JM, Alric L, Rosa I, Kamar N, Izopet J. Performance of anti-HEV assays for diagnosis of acute hepatitis $\mathrm{E}$ in immunocompromised patients. J. Clin. Virol. 4 November 2013.

19. Davern TJ, Chalasani N, Fontana RJ, Hayashi PH, Protiva P, Kleiner $\mathrm{DE}$, Engle RE, Nguyen H, Emerson SU, Purcell RH, Tillmann HL, Gu J, Serrano J, Hoofnagle JH.. Acute hepatitis E infection accounts for some cases of suspected drug-induced liver injury. Gastroenterology 2011; 141:1665-1672.

20. van der Valk M, Zaaijer HL, Kater AP, Schinkel J. Sofosbuvir shows antiviral activity in a patient with chronic hepatitis $E$ virus infection. $J$ Hepatol. 2017;66(1):242-243. 